\title{
The Wheat Dwarf India Virus-Betasatellite Complex Has a Wider Host Range Than Previously Reported
}

\author{
Jitendra Kumar, ${ }^{1}$ Sachin Kumar, ${ }^{2}$ and Shahryar F. Kianian ${ }^{3,+}$ \\ ${ }^{1}$ Department of Plant Pathology, University of Minnesota, St. Paul, MN, U.S.A. \\ ${ }^{2}$ Department of Genetics and Plant Breeding, Chaudhary Charan Singh University, Meerut, Uttar Pradesh, India \\ ${ }^{3}$ USDA-ARS Cereal Disease Laboratory, St. Paul, MN, U.S.A.
}

Accepted for publication 15 March 2020.

\section{Abstract}

Wheat dwarf India virus (WDIV) and associated alphasatellite and betasatellite have been documented to infect wheat (Triticum aestivum). Here, we report, for the first time, presence of WDIV and the associated Ageratum yellow leaf curl betasatellite (AYLCB) in barley (Hordeum vulgare) and sugarcane (Saccharum officinarum) in addition to wheat. However, surprisingly, the previously reported alphasatellites were not detected in the WDIV-positive barley, sugarcane, and wheat samples. The virus and betasatellite detected from barley, sugarcane, and wheat showed high levels of sequence identity to the previously reported WDIV and AYLCB. The study shows that WDIV may have much wider host range than previously documented.

Keywords: WDIV, satellites, host range, barley, sugarcane
Members of the genus Mastrevirus, family Geminiviridae, infect either dicotyledonous (dicot) or monocotyledonous (monocot) hosts and are transmitted by leafhoppers (Boulton 2002). They have a monopartite circular ssDNA genome of 2.5 to $2.7 \mathrm{~kb}$ that codes for the movement protein (MP; open reading frame $[\mathrm{ORF}] \mathrm{V} 2$ ) and coat protein (CP; V1) on the virion-sense strand and replicationassociated proteins (Rep and RepA) on the complementary-sense strand (Boulton 2002). RepA is translated from a nonspliced transcript that spans the $\mathrm{C} 1$ and $\mathrm{C} 2 \mathrm{ORFs}$, whereas Rep is translated from a spliced transcript that fuses $\mathrm{C} 1$ and C2 ORFs (Hefferon and Dugdale 2003; Wright et al. 1997). The genes on the virion and complementary strands are separated by the large intergenic region (LIR) and small intergenic region (SIR). The LIR contains a characteristic stem loop structure with the invariant nonanucleotide sequence (TAATATTAC) (Boulton 2002; Lazarowitz et al. 1989).

${ }^{\dagger}$ Corresponding author: S. F. Kianian; Shahryar.Kianian@ars.usda.gov

Mention of trade names or commercial products in this publication is solely for purpose of providing specific information and does not imply recommendation or endorsement by the U.S. Department of Agriculture. USDA is an equal opportunity provider and employer.

Funding: Funding for the project was provided by the U.S. Department of Agriculture - Agricultural Research Service and the Minnesota State Agricultural Experiment Station (co-operative agreement between USDA-ARS and University of Minnesota: 58-5062-8-015).

*The $\boldsymbol{e}$-Xtra logo stands for "electronic extra" and indicates that two supplementary figures and two supplementary files are published online.

The author(s) declare no conflict of interest.

This article is in the public domain and not copyrightable. It may be freely reprinted with customary crediting of the source. The American Phytopathological Society, 2020
Recently, two mastreviruses, wheat dwarf India virus (WDIV) and chickpea chlorotic dwarf virus (CpCDV), have been reported to be associated with satellites (Hamza et al. 2018; Kumar et al. 2014a, 2014b, 2015). Importantly, the associated satellites have been documented to enhance the severity of WDIV and CpCDV disease symptoms (Hamza et al. 2018; Kumar et al. 2014a, 2014b). WDIV is a monocot-infecting mastrevirus and has been reported to be associated with cotton leaf curl Multan alphasatellite (CLCuMuA) and guar leaf curl alphasatellite of the family Alphasatellitidae and Ageratum yellow leaf curl betasatellite (AYLCB) of the family Tolecusatellitidae (Adams et al. 2017; Briddon et al. 2018; Kumar et al. 2012, 2014a, 2014b, 2015). The presence of WDIV and associated alpha- and betasatellites was documented from several geographical regions in India, which demonstrate a strong association between WDIV and the satellites (Kumar et al. 2015). On the other hand, CpCDV is a dicot-infecting mastrevirus and was found to be associated with cotton leaf curl Multan betasatellite, of the family Tolecusatellitidae, and CLCuMuA in field infections of spinach (Hamza et al. 2018).

The present study reports the presence of WDIV and associated betasatellite in symptomatic barley (Hordeum vulgare), sugarcane (Saccharum officinarum), and wheat (Triticum aestivum) samples from India. The symptomatic barley and wheat plants had dwarfing and/or yellowing symptoms, whereas the sugarcane plants showed chlorotic streaks on the leaves (Fig. 1). Leaf samples from six barley, 11 sugarcane, and six wheat plants were collected during 2017 to 2018 from farmers and research fields in India (Meerut, Uttar Pradesh; latitude, $28.96^{\circ} \mathrm{N}$; longitude, $77.74^{\circ} \mathrm{E}$ ). Young leaf samples from symptomatic and nonsymptomatic barley, sugarcane, and wheat plants were collected and stored in separate tubes with ethanol at room temperature for 1 week. Then the ethanol was decanted, and the dried leaf samples were stored in a freezer until further use. 


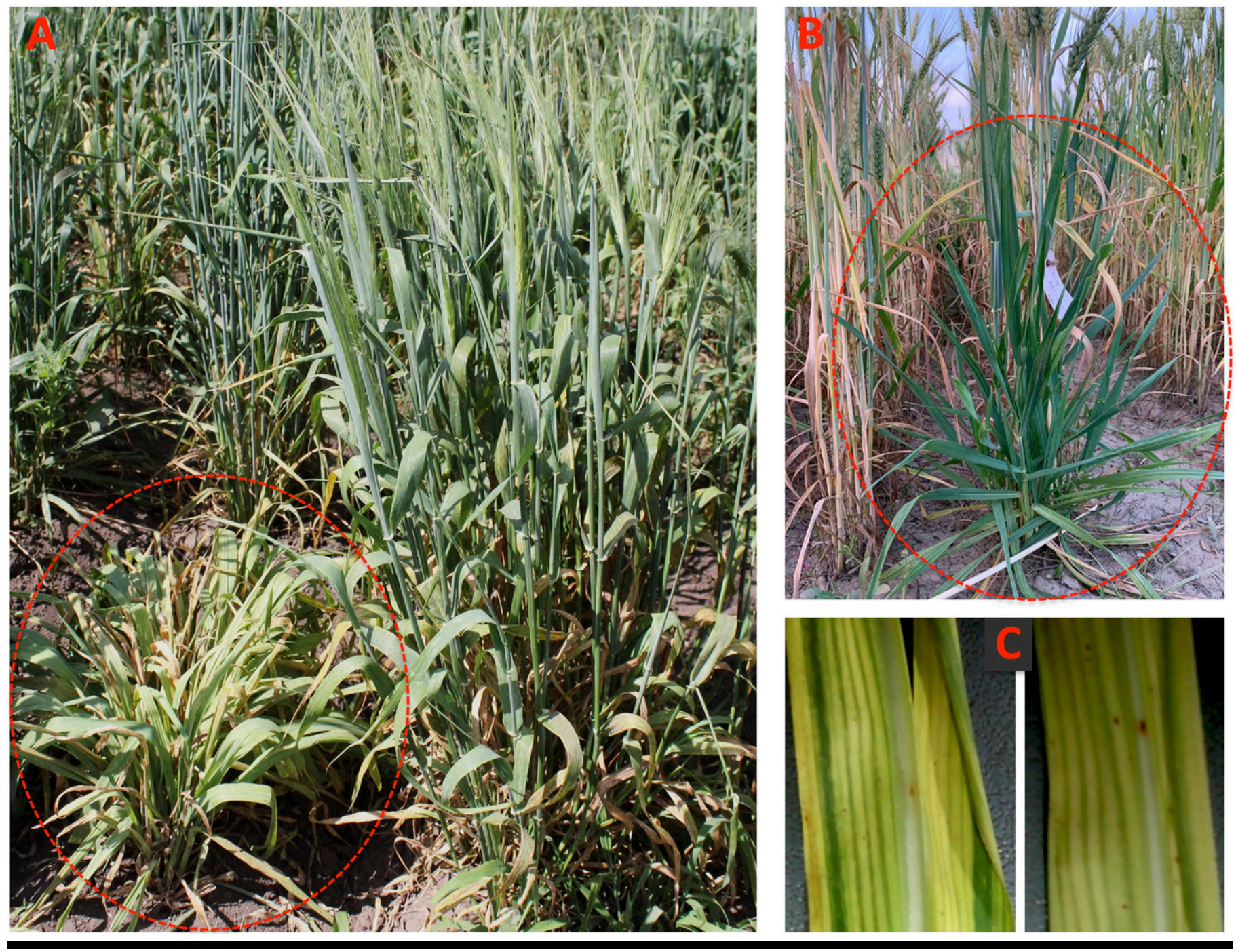

FIGURE 1

Wheat dwarf India virus- and Ageratum yellow leaf curl betasatellite-infected barley (A) and wheat (B) plants are shown in red circles. Leaves of an infected sugarcane plant showing chlorotic streak symptoms (C).

\section{Detection and Analysis of Virus and Satellite Genomes}

Total DNA was isolated from the dried leaf samples using a modified sodium dodecyl sulfate method (Edwards et al. 1991) and quantified using a NanoDrop (Thermo Scientific, Waltham, MA). Approximately $100 \mathrm{ng}$ of total DNA was used as a template in polymerase chain reaction (PCR). PCR-based amplification of WDIV and the satellite DNA was performed using specific primers (Table 1), which yielded fragments of the sizes expected for WDIV and betasatellite. A total of three barley, four sugarcane, and two wheat samples tested positive for WDIV. The nine WDIV-positive samples also tested positive for AYLCB. However, the PCR reactions using primers published earlier (Bull et al. 2003; Kumar et al. 2010) and primers designed as part of the study here (Table 1) for alphasatellite did not yield a fragment from any of the samples. The PCR products obtained using WDVKF/R and Beta01/04 primer pairs and representing WDIV and betasatellite genomes, respectively, were cloned in pJET1.2 cloning vector (Thermo Scientific). Three clones for WDIV and AYLCB from each of nine samples were selected for partial sequencing to confirm their identity. Upon confirmation of the identity, one clone for virus and one for betasatellite from each of the two barley, three sugarcane, and two wheat samples were sequenced in entirety. The full-length sequences of the virus and satellite genomes were assembled using CAP3 program (Huang and Madan 1999). Phylogenetic analysis was performed using Molecular Evolutionary Genetics Analysis software, MEGA version 7 (Kumar et al. 2016).

\section{Analysis of the Virus and Satellite Genomes}

The virus genome amplified from the samples was $2,783 \mathrm{bp}$ (Table 2) and showed sequence identities of 98 to $99 \%$ with WDIV reported previously (Kumar et al. 2012). The phylogenetic analysis showed the newly characterized WDIV sequences isolated from barley, sugarcane, and wheat form a separate cluster with the previously reported WDIV isolates, whereas viruses belonging to other species clustered separately (Supplementary Fig. 1). Based on the nucleotide sequence identity and the phylogenetic analysis, the newly characterized viruses are isolates/variants of WDIV.

ORFs of the WDIV clones were determined using the ORF finder tool (https://www.ncbi.nlm.nih.gov/orffinder/). The analysis showed four ORFs (V1, V2, C1, and C2) and two intergenic regions (LIR and SIR), which were conserved in sequence and position between all of the clones. The LIR harbors a predicted stem-loop 
structure with the nonanucleotide sequence TAATATTAC as also documented previously (Boulton 2002; Kumar et al. 2014a; Lazarowitz et al. 1989). The complete nucleotide sequences of one clone from each of the two barley, three sugarcane, and two wheat samples were submitted to GenBank (Table 2).

Betasatellite sizes ranged from 1,362 to 1,365 bp (Table 2) and showed sequence identities of $99 \%$ with AYLCB reported previously from wheat (Kumar et al. 2014a, 2014b). The phylogenetic tree shows the seven betasatellite sequences determined here to cluster with AYLCB sequences previously isolated from wheat, and

\section{TABLE 1}

List of primers used during the present study ${ }^{a}$

\begin{tabular}{lll} 
Primer name & \multicolumn{1}{c}{ Nucleotide sequence $\left(\mathbf{5}^{\prime} \mathbf{- 3}^{\prime}\right)$} & Target \\
WDVHF* & AAGCTTAGGAAGCTCCCGGT & WDIV \\
WDVHR & AAGCTTGGTCGCCGATCCTTT & WDIV \\
WDVKF* & GGTACCTGAAGGTTGAAGACGA & WDIV \\
WDVKR* & GGTACCGCAGTAATAACTGCTT & WDIV \\
Beta01** & GAAACCACTACGCTACGCAGC & Beta \\
Beta04** & ACCCTCCCAGGGGTACACACCG & Beta \\
Nanofor** & AAGTGGGTCCTGGTTCTA & Alpha \\
Nanorev** & CTGTACAGGTCTCTGGC & Alpha \\
DNA101** & CTGCAGATAATGTAGCTTACCAG & Alpha \\
DNA102** & CTGCAGATCCTCCACGTGTATAG & Alpha \\
AlphaPstF* & CTGCAGATAAVGTWYVRTWD & Alpha \\
AlphaPstR* & CTGCAGATCCWCKKSMMMWW & Alpha \\
Alpha1F* & GTAATTCGAAGTCCGGTGAGA & Alpha \\
Alpha1R* & AGATTCTCGTTGTCGTCGTT & Alpha \\
Alpha2F* & ACGAAGCTCGGGATTACTGTA & Alpha \\
Alpha2R* & CGGTCTTACGCGCACGTTGTT & Alpha \\
Alpha3F* & GACGACTCGACGACGCCACT & Alpha \\
Alpha3R* & GGCGACTCTTCTTCCTGCCA & Alpha \\
\hline
\end{tabular}

a Underlined nucleotides represent restriction sites. Primers with “*” were designed as a part of the present study, whereas the primers with "***" were designed by Kumar et al. (2010) and Bull et al. (2003). WDIV = wheat dwarf India virus; Beta = betasatellite; and Alpha = alphasatellite . they are distinct from other betasatellites species (Supplementary Fig. 2). Based on the full-length nucleotide sequence identity and the phylogenetic analysis, the newly characterized betasatellites are isolates/variants of AYLCB.

Sequence analysis showed a genome organization typical of betasatellites. The betasatellites contain an adenine-rich region, a $\beta C 1$ gene, and a sequence of approximately 150 nucleotidesknown as a satellite conserved region-conserved between all betasatellites that encompasses a predicted hairpin structure that contains the nonanucleotide sequence TAATATTAC. The nucleotide sequences of betasatellites were submitted to GenBank (Table 2).

\section{Association of Satellites and Host Range}

This is the first report on the presence of WDIV and AYLCB in barley and sugarcane in field infections. The WDIV sequences isolated from the barley, sugarcane, and wheat have high levels of nucleotide sequence identity (98 to $99 \%$ ). This shows that WDIV has a much wider host range than previously documented (Kumar et al. 2012, 2014a, 2015).

In previous studies (Kumar et al. 2014a, 2015), both alphasatellite and betasatellite were found to be nearly ubiquitously associated with WDIV infection across different geographical regions in India. However, the alphasatellite was not detected in barley, sugarcane, and wheat during the present investigation.

Although the reason is unclear, WDIV seems to prefer to associate with betasatellites as compared with alphasatellites. Betasatellites have been reported to be involved in mitigating antiviral resistance, enhanced virus accumulation, pathogenicity determination, and movement inside the host plant (Saeed et al. 2005; Saunders et al. 2004; Tahir and Mansoor 2011). On the other hand, things are less clear for alphasatellites. Some of the alphasatellites have been shown to have transcriptional and posttranscriptional gene silencing and to enhance symptoms and accumulation of the virus, whereas others have been reported to be associated with reduction of betasatellite and viral DNA accumulation and attenuation of the disease symptoms (Abbas et al. 2019; Idris et al. 2011; Kumar et al. 2014a; Mar et al. 2017; Nawaz-ul-Rehman et al. 2010; Vinoth Kumar et al. 2017; Wu and Zhou 2005).

Because betasatellites enhance symptoms, the presence of a betasatellite with WDIV in infected wheat, barley, and sugarcane

\begin{tabular}{|c|c|c|c|c|c|c|c|c|c|}
\hline \multirow{2}{*}{$\begin{array}{l}\text { Virus/satellite name } \\
\text { (acronym) }\end{array}$} & \multicolumn{9}{|c|}{$\begin{array}{c}\text { TABLE } 2 \\
\text { Names, accession numbers, and gene coordinates of the virus and betasatellites }{ }^{\mathrm{a}}\end{array}$} \\
\hline & Host & $\begin{array}{l}\text { Sample } \\
\text { number }\end{array}$ & $\begin{array}{l}\text { Size of the } \\
\text { clone (bp) }\end{array}$ & $\begin{array}{l}\text { Accession } \\
\text { number }\end{array}$ & \multicolumn{5}{|c|}{ Gene coordinates } \\
\hline \multirow{5}{*}{$\begin{array}{l}\text { Wheat dwarf India virus } \\
\text { (WDIV) }\end{array}$} & \multirow[t]{2}{*}{ Barley } & Bar2 & 2,783 & MN273439 & \multirow{5}{*}{$\begin{array}{l}\text { (V-strand) } \\
175 \text { to } \\
495\end{array}$} & \multirow{5}{*}{$\begin{array}{l}\text { (V-strand) } \\
540 \text { to } \\
1,283\end{array}$} & \multirow{5}{*}{$\begin{array}{c}\text { (C-strand) } \\
1,728 \text { to } \\
2,597\end{array}$} & \multirow{5}{*}{$\begin{array}{l}\text { (C-strand) join } 1,435 \text { to } \\
1,810 \text { and } 1,900 \text { to } \\
2,597\end{array}$} & \multirow[t]{5}{*}{ NA } \\
\hline & & Bar5 & 2,783 & MN273440 & & & & & \\
\hline & Sugarcane & Sug4 & 2,783 & MN273441 & & & & & \\
\hline & \multirow[t]{2}{*}{ Wheat } & Wh2 & 2,783 & MN273444 & & & & & \\
\hline & & Wh5 & 2,783 & MN273445 & & & & & \\
\hline \multirow{4}{*}{$\begin{array}{l}\text { Ageratum yellow leaf } \\
\text { curl betasatellite } \\
\text { (AYLCB) }\end{array}$} & \multirow[t]{2}{*}{ Barley } & Bar2 & 1,364 & MN273446 & \multirow[t]{4}{*}{ NA } & \multirow[t]{4}{*}{ NA } & \multirow[t]{4}{*}{ NA } & \multirow[t]{4}{*}{ NA } & \multirow{4}{*}{$\begin{array}{l}\text { (C-strand) } \\
180 \text { to } \\
596\end{array}$} \\
\hline & & Bar5 & 1,364 & MN273447 & & & & & \\
\hline & \multirow[t]{2}{*}{ Sugarcane } & Sug 4 & 1,364 & MN273448 & & & & & \\
\hline & & Sug6 & 1,362 & MN273449 & & & & & \\
\hline
\end{tabular}

${ }^{\mathrm{a}} \mathrm{NA}=$ not applicable; $\mathrm{V}=$ virion $\mathrm{C}=$ complementary; $\mathrm{MP}=$ movement protein $; \mathrm{CP}=$ coat protein; $\mathrm{RepA}=$ replication associated protein- $\mathrm{A} ; \mathrm{Rep}=$ replication associated protein; and $\beta \mathrm{C} 1=\mathrm{C} 1$ protein of betasatellite. 
has serious implications. More severe symptoms will lead to greater crop losses and economic impact. Considering the findings present here, it will be of interest to examine further barley, sugarcane, wheat, and other plant species to determine the geographical and host range of this mastrevirus-betasatellite complex.

\section{Literature Cited}

Abbas, Q., Amin, I., Mansoor, S., Shafiq, M., Wassenegger, M., and Briddon, R. W. 2019. The Rep proteins encoded by alphasatellites restore expression of a transcriptionally silenced green fluorescent protein transgene in Nicotiana benthamiana. VirusDisease 30:101-105.

Adams, M. J., Lefkowitz, E. J., King, A. M. Q., Harrach, B., Harrison, R. L., Knowles, N. J., Kropinski, A. M., Krupovic, M., Kuhn, J. H., Mushegian, A. R., Nibert, M., Sabanadzovc, S., Sanfacon, H., Siddell, S. G., Simmonds, P., Varsani, A., Zerbini, F. M., Gorbalenya, A. E., and Davison, A. J. 2017. Changes to taxonomy and the international code of virus classification and nomenclature ratified by the International Committee on Taxonomy of $\mathrm{Vi}$ ruses (2017). Arch. Virol. 162:2505-2538.

Boulton, M. I. 2002. Functions and interactions of mastrevirus gene products. Physiol. Mol. Plant Pathol. 60:243-255.

Briddon, R. W., Martin, D. P., Roumagnac, P., Navas-Castillo, J., Fiallo-Olivé, E., Moriones, E., Lett, J. M., Zerbini, F. M., and Varsani, A. 2018. Alphasatellitidae: A new family with two subfamilies for the classification of geminivirus- and nanovirus-associated alphasatellites. Arch. Virol. 163: 2587-2600.

Bull, S. E., Briddon, R. W., and Markham, P. G. 2003. Universal primers for the PCR-mediated amplification of DNA 1: A satellite-like molecule associated with begomovirus-DNA beta complexes. Mol. Biotechnol. 23:83-86.

Edwards, K., Johnstone, C., and Thompson, C. 1991. A simple and rapid method for the preparation of plant genomic DNA for PCR analysis. Nucleic Acids Res. 19:1349.

Hamza, M., Tahir, M. N., Mustafa, R., Kamal, H., Khan, M. Z., Mansoor, S., Briddon, R. W., and Amin, I. 2018. Identification of a dicot infecting mastrevirus along with alpha- and betasatellite associated with leaf curl disease of spinach (Spinacia oleracea) in Pakistan. Virus Res. 256:174-182.

Hefferon, K. L., and Dugdale, B. 2003. Independent expression of Rep and RepA and their roles in regulating bean yellow dwarf virus replication. J. Gen. Virol. 84:3465-3472.

Huang, X., and Madan, A. 1999. CAP3: A DNA sequence assembly program. Genome Res. 9:868-877.

Idris, A. M., Shahid, M. S., Briddon, R. W., Khan, A. J., Zhu, J. K., and Brown, J. K. 2011. An unusual alphasatellite associated with monopartite begomoviruses attenuates symptoms and reduces betasatellite accumulation. J. Gen. Virol. 92:706-717.
Kumar, J., Kumar, A., Roy, J. K., Tuli, R., and Khan, J. A. 2010. Identification and molecular characterization of begomovirus and associated satellite DNA molecules infecting Cyamopsis tetragonoloba. Virus Genes 41:118-125.

Kumar, J., Kumar, J., Singh, S., Shukla, V., Singh, S. P., and Tuli, R. 2015. Prevalence of wheat dwarf India virus in wheat in India. Curr. Sci. 108: 260-265.

Kumar, J., Kumar, J., Singh, S. P., and Tuli, R. 2014a. Association of satellites with a mastrevirus in natural infection: Complexity of wheat dwarf India virus disease. J. Virol. 88:7093-7104.

Kumar, J., Kumar, J., Singh, S. P., and Tuli, R. 2014b. $\beta C 1$ is a pathogenicity determinant: Not only for begomoviruses but also for a mastrevirus. Arch. Virol. 159:3071-3076.

Kumar, J., Singh, S. P., Kumar, J., and Tuli, R. 2012. A novel mastrevirus infecting wheat in India. Arch. Virol. 157:2031-2034.

Kumar, S., Stecher, G., and Tamura, K. 2016. MEGA7: Molecular Evolutionary Genetics Analysis version 7.0 for bigger datasets. Mol. Biol. Evol. 33: 1870-1874.

Lazarowitz, S. G., Pinder, A. J., Damsteegt, V. D., and Rogers, S. G. 1989. Maize streak virus genes essential for systemic spread and symptom development. EMBO J. 8:1023-1032.

Mar, T. B., Mendes, I. R., Lau, D., Fiallo-Olivé, E., Navas-Castillo, J., Alves, M. S., and Zerbini, F. M. 2017. Interaction between the New World begomovirus Euphorbia yellow mosaic virus and its associated alphasatellite: Effects on infection and transmission by the whitefly Bemisia tabaci. J. Gen. Virol. 98:1552-1562.

Nawaz-ul-Rehman, M. S., Nahid, N., Mansoor, S., Briddon, R. W., and Fauquet, C. M. 2010. Post-transcriptional gene silencing suppressor activity of two non-pathogenic alphasatellites associated with a begomovirus. Virology 405 : 300-308.

Saeed, M., Behjatnia, S. A. A., Mansoor, S., Zafar, Y., Hasnain, S., and Rezaian, M. A. 2005. A single complementary-sense transcript of a geminiviral DNA $\beta$ satellite is determinant of pathogenicity. Mol. Plant-Microbe Interact. 18: $7-14$

Saunders, K., Norman, A., Gucciardo, S., and Stanley, J. 2004. The DNA $\beta$ satellite component associated with Ageratum yellow vein disease encodes an essential pathogenicity protein $(\beta C 1)$. Virology 324:37-47.

Tahir, M. N., and Mansoor, S. 2011. $\beta \mathrm{C} 1$ of chili leaf curl betasatellite is a pathogenicity determinant. Virol. J. 8:509.

Vinoth Kumar, R., Singh, D., Singh, A. K., and Chakraborty, S. 2017. Molecular diversity, recombination and population structure of alphasatellites associated with begomovirus disease complexes. Infect. Genet. Evol. 49:39-47.

Wright, E. A., Heckel, T., Groenendijk, J., Davies, J. W., and Boulton, M. I. 1997. Splicing features in maize streak virus virion- and complementarysense gene expression. Plant J. 12:1285-1297.

Wu, P.-J., and Zhou, X. 2005. Interaction between a nanovirus-like component and the tobacco curly shoot virus/satellite complex. Acta Biochim. Biophys. Sin. (Shanghai) 37:25-31. 